\title{
Aging Effect on Characteristics of Oil Impregnated Insulation Paper for Power Transformers
}

\author{
Loai S. Nasrat ${ }^{1}$, Nesrine Kassem ${ }^{2}$, Nadia Shukry ${ }^{2}$ \\ ${ }^{1}$ Electrical Engineering Department, Faculty of Engineering, South Valley University, Aswan, Egypt \\ ${ }^{2}$ Cellulose and Paper Department, National Research Center, Cairo, Egypt \\ Email: loaisaad@yahoo.com
}

Received September 11, 2012; revised October 10, 2012; accepted October 21, 2012

\begin{abstract}
This paper deals with experimental investigations of the electrical and physical properties of oil impregnated insulation paper for power transformers at different temperatures. The ac breakdown voltage, tensile strength and water content of insulation papers impregnated in mineral oil for different time periods were investigated. The effect of insulation paper thickness on the electrical and mechanical properties has also been studied. The results showed that the breakdown voltage and the tensile strength decreased with increasing the time of immersion of insulation paper in oil at room temperature, at 5 and at $-12^{\circ} \mathrm{C}$. Also, the thermal aging effect on the characteristic of insulation paper has been studied. It was found that high temperatures affect the breakdown voltage and the tensile strength to a great extent.
\end{abstract}

Keywords: Insulation Paper; Power Transformers; Aging; Breakdown Voltage; Tensile Strength; Water Content

\section{Introduction}

Transformers play an important role in providing a reliable and efficient electricity supply and represent the most critical equipments in electric power transmission and distribution systems $[1,2]$. In the early days, only a few insulation materials were known for low temperature superconducting power applications [3]. Paper was one of the first insulation materials used in high voltage technology [4]. Since winding techniques were common in the cable industry, kraft paper was used in transformers and high capacity cables. The thermal contraction of paper is low enough and elastic elongation at low temperatures is reasonable without leading to mechanical problems. Moreover, paper is very cheap compared to plastic tapes. Recently, other materials have been used in prototypes specifically for large scale high temperature superconductivity (HTS) applications such as transformers $[5,6]$. However, paper can still be used in HTS transformers [7].

Oil filled power transformers have a composite liquidsolid insulation structure, where the oil-impregnated papers are used for both mechanical and electrical purposes. Oil impregnated papers gradually age due to thermal stress, moisture and acidity; and their degradation affects the lifetime of the power transformers $[8,9]$.

In this study, the aim is to examine how aging affects the mechanical, electrical and physical characteristics of oil impregnated papers. The study presents experimental results of oil impregnated paper breakdown strength un- der ac $(50 \mathrm{~Hz})$ voltage. Also, physical and mechanical measurements have been investigated namely: moisture content and tensile strength.

\section{Experimental}

Mineral oil impregnated insulation kraft papers with various thicknesses $(0.2,0.3$ and $0.4 \mathrm{~mm})$ have been examined in this study. Two different sets were carried out. In the first set, samples were impregnated in mineral oil for $21,35,56$ and 77 days at temperatures: $23^{\circ} \mathrm{C}$ (Room Temp.), $5^{\circ} \mathrm{C}$ and $-12^{\circ} \mathrm{C}$. In the second set, the samples were subjected to thermal aging conditions by using an oven. The testing temperatures were controlled and ranged from $110^{\circ} \mathrm{C}$ to $170^{\circ} \mathrm{C}$. Three different thermal aging intervals have been selected (48, 72 and 96 hours). Analysis of electrical, mechanical and physical properties of oil impregnated papers was carried out.

\subsection{AC Breakdown Voltage of Oil Impregnated Paper}

The ac breakdown voltage was measured according to ASTM D 149 using two electrodes which were $25 \mathrm{~mm}$ diameter brass cylinder types. A single phase auto transformer having a $5 \mathrm{kVA}-100 \mathrm{kV}-50 \mathrm{~Hz}$, Terco type HV 9105, has been used. The oil impregnated paper was cut into circular samples with a diameter of $42 \mathrm{~mm}$. For each test, five oil impregnated paper samples were tested, and the average value was calculated. The voltage was 
applied at a rise rate of $2 \mathrm{kV} / \mathrm{s}$ until breakdown occurs.

\subsection{Water Content of Oil Impregnated Paper [10]}

An accurate weight of the air dried sample $\left(\mathrm{W}_{2}\right)$ is heated at $105^{\circ} \mathrm{C}$ till constant weight and then reweighed $\left(\mathrm{W}_{1}\right)$. The moisture content was calculated using the formula: $\%$ Water content $=\left(\mathrm{W}_{2}-\mathrm{W}_{1}\right) \times 100 / \mathrm{W}_{1}$.

\subsection{Tensile Strength of Oil Impregnated Paper}

It is estimated according to the German Standard Method [11] on LLOYD LR 10K instrument. A paper strip of 15 $\mathrm{mm}$ wide and $15 \mathrm{~cm}$ length was clamped at each end between the two jaws, and an increasing load was applied causing the clamps to move apart until the strip breaks at a certain force. Tensile Strength

$=$ Force $(\mathrm{N}) /$ Paper thickness $\times$ width $\left(\mathrm{mm}^{2}\right)$.

\section{Results and Discussion}

In the last decades, dielectric testing techniques are being used and investigated as potential tools for condition assessment of oil-paper insulation. From fields and laboratory investigations, these techniques were found to be highly operating conditions (water content, aging, temperature, etc.) dependent.

\subsection{Effect of Low Temperatures on Properties of Oil Impregnated Papers}

\subsubsection{Effect on AC Breakdown Voltage}

The experimental results of ac breakdown voltage for different thicknesses $(0.2,0.3$ and $0.4 \mathrm{~mm})$ of oil impregnated papers immersed at various temperatures (RT, $5^{\circ} \mathrm{C}$ and $-12^{\circ} \mathrm{C}$ ) up to 77 days are shown in Figures 1-3.

Figure 1 represents the relationship between time of immersing insulation papers $(21,35,56$ and 77 days) with thickness $0.2 \mathrm{~mm}$ and breakdown voltages at $23^{\circ} \mathrm{C}$ (RT), $5^{\circ} \mathrm{C}$ and $-12^{\circ} \mathrm{C}$, respectively.

It can be seen from this figure that, as the time of immersed papers in oil increased, the breakdown voltage decreased for all tested temperatures. The value of breakdown of the blank insulation paper is $13.11 \mathrm{kV}$. The breakdown voltages were 12.14, 11.92, 11.41 and 11.26 $\mathrm{kV}$ for times 21, 35, 56 and 77 days, respectively, at room temperature (RT) $23^{\circ} \mathrm{C}$. By decreasing the temperature to $5^{\circ} \mathrm{C}$, the breakdown voltages were 12.31 , $12.26,11.84$ and $11.69 \mathrm{kV}$ for times $21,35,56$ and 77 days, respectively; whereas at $-12^{\circ} \mathrm{C}$, the breakdown voltages were $12.64,12.51,12.25$ and $11.98 \mathrm{kV}$ for the same time intervals.

Figure 2 illustrates the same relationship for impregnating paper having $0.3 \mathrm{~mm}$ thickness. The results took the same trend as for samples having $0.2 \mathrm{~mm}$, but with

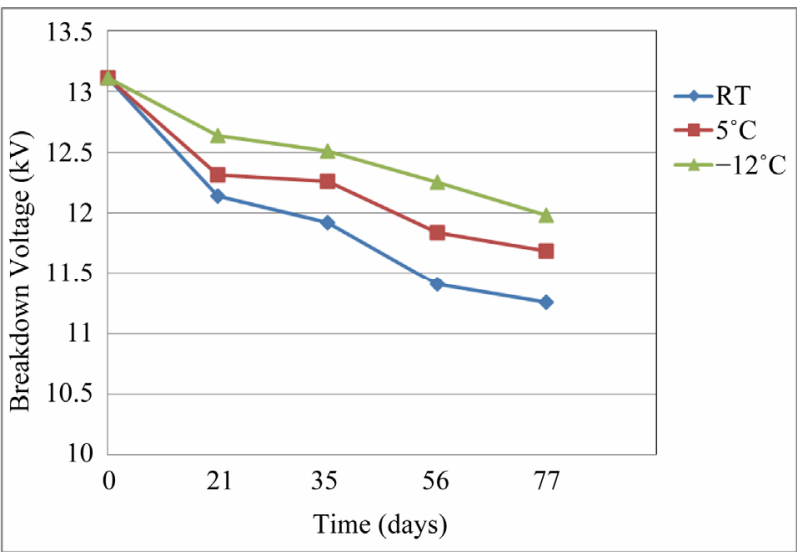

Figure 1. Breakdown voltage of insulation paper with 0.2 $m m$ thickness immersed in oil at $\mathrm{RT}, 5^{\circ} \mathrm{C}$ and $-12^{\circ} \mathrm{C}$.

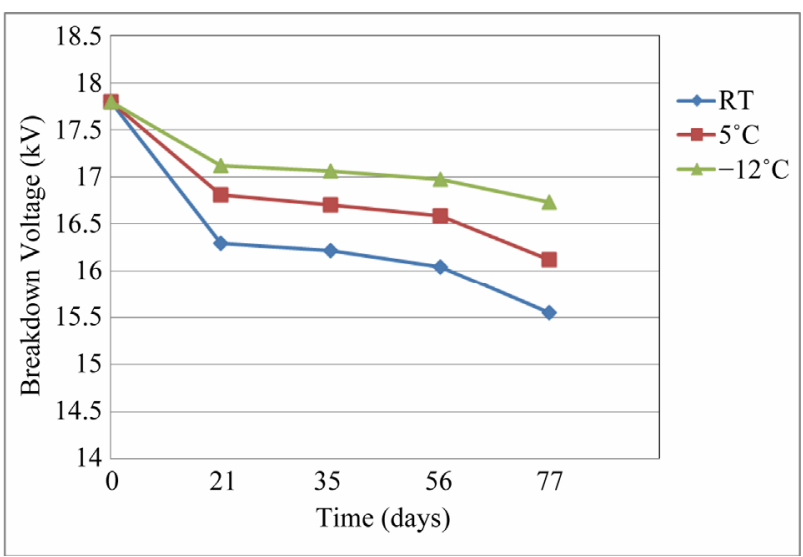

Figure 2. Breakdown voltage of insulation paper with 0.3 $\mathrm{mm}$ thickness immersed in oil at $\mathrm{RT}, 5^{\circ} \mathrm{C}$ and $-12^{\circ} \mathrm{C}$.

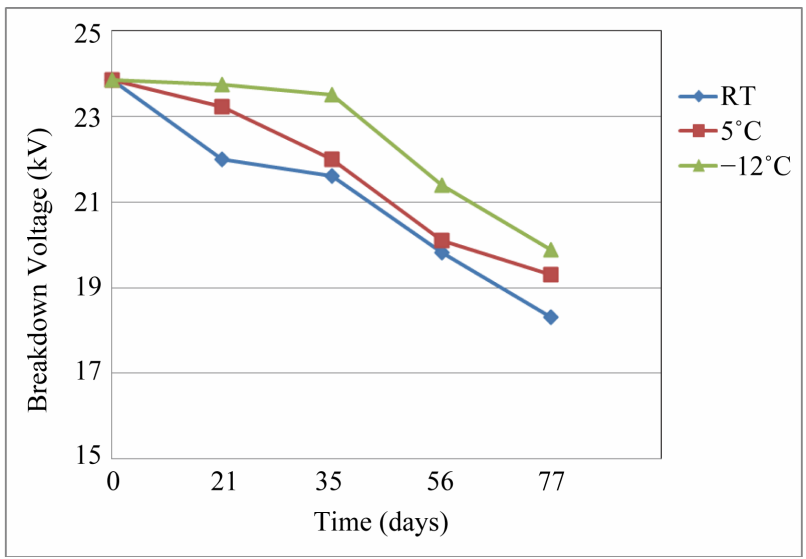

Figure 3. Breakdown voltage of insulation paper with 0.4 mm thickness immersed in oil at $\mathrm{RT}, 5^{\circ} \mathrm{C}$ and $-12^{\circ} \mathrm{C}$.

higher values of breakdown voltages. For example, after 21 days, the breakdown voltages were 16.30, 16.81 and $17.12 \mathrm{kV}$ for temperatures $\mathrm{RT}, 5^{\circ} \mathrm{C}$ and $-12^{\circ} \mathrm{C}$ respectively. After 35 days, the breakdown voltages were 16.22, 16.70 and $17.06 \mathrm{kV}$ for the same temperatures. Increas- 
ing the time to 56 days, the breakdown voltages were $16.04,16.59$ and $16.97 \mathrm{kV}$ for the mentioned temperatures. When the time reached 77 days, the breakdown voltages were $15.55,16.12$ and $16.73 \mathrm{kV}$. From these results, it can be concluded that, as the temperature decreases from $23^{\circ} \mathrm{C}(\mathrm{RT})$ to $-12^{\circ} \mathrm{C}$, the breakdown voltage increases for all time periods.

For oil impregnated papers with thickness $0.4 \mathrm{~mm}$, the breakdown voltage against time at $\mathrm{RT}, 5^{\circ} \mathrm{C}$ and $-12^{\circ} \mathrm{C}$ is plotted in Figure 3.

From this figure, it is clear that the relationship took approximately the same trend, whereas the breakdown voltage was $23.86 \mathrm{kV}$ for the blank specimen. The breakdown voltages were $22,21.62,19.82$ and $18.31 \mathrm{kV}$ for $21,35,56$ and 77 days, respectively, at RT. Whereas, at $5^{\circ} \mathrm{C}$ the breakdown voltage were $23.22,22,20.11$ and $19.31 \mathrm{kV}$ for the same time internals. By decreasing the temperature to $-12^{\circ} \mathrm{C}$, the breakdown voltages were 23.74, 23.51, 21.39 and $19.88 \mathrm{kV}$, for $21,35,56$ and 77 days, respectively. It can therefore be concluded that the breakdown voltage of oil impregnated insulation paper has been affected by thickness of paper, oil temperature and impregnation time.

\subsubsection{Effect on Tensile Strength}

Paper is essentially cellulose, a linear polysaccharide consisting of many $\beta$-D-glucopyranose units linked to each other via (1-4)glycosidic bond to form a polymeric chain. The strength of paper is a result of the oriented linear chains and hydrogen bonding between the chains, which adds to rigidity (Scheme 1). Tensile strength provides a relative indication of the number of intact molecular chains and the degree of hydrogen bonding between the chains. Reduction of tensile strength indicates that scission of these chains has taken place.

The effect of different thicknesses, temperatures and time intervals on tensile strength of oil impregnated paper samples are shown in Figures 4-7. From these figures, it can be seen that the increase of the time of impregnation of samples at RT resulted in a gradual decrease in the tensile strength of paper. The tensile strength decreased by $9.7 \%, 14.4 \%, 23.1 \%$ and $25 \%$ from its original value for samples of $0.2 \mathrm{~mm}$ thickness at room temperature for times $21,35,56$ and 77 days respectively. For samples of $0.3 \mathrm{~mm}$ thickness, the decrease was $3.5 \%, 18.8 \%, 26.4 \%$ and $16.7 \%$ from its original value for the same time intervals. The tensile strengths of the samples of $0.4 \mathrm{~mm}$ thickness have decreased by $9.6 \%, 11.1 \%, 17.8 \%$ and $13.3 \%$, respectively for the same time intervals. From the previous values, it can be noticed that when the papers were impregnated for 77 days, they gained a small percentage of the tensile strength may be due to relative decrease in moisture content (will be discussed later).

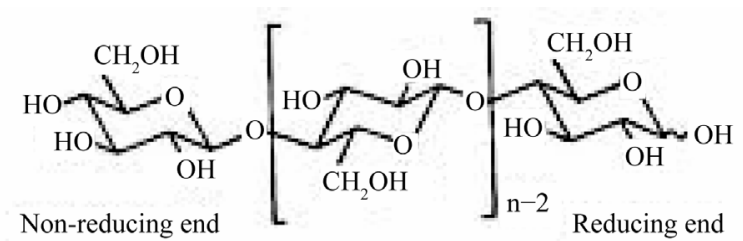

Sometimes shown as

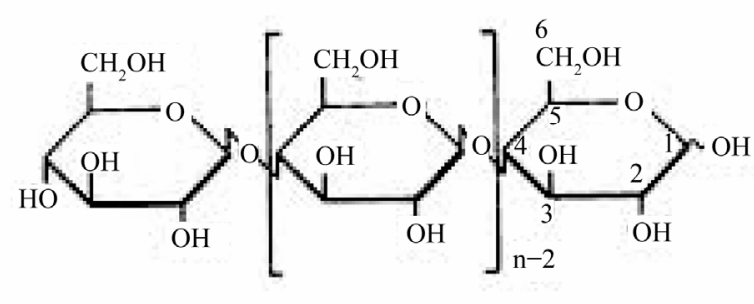

Cellulose

Scheme 1. Structure of cellulose.

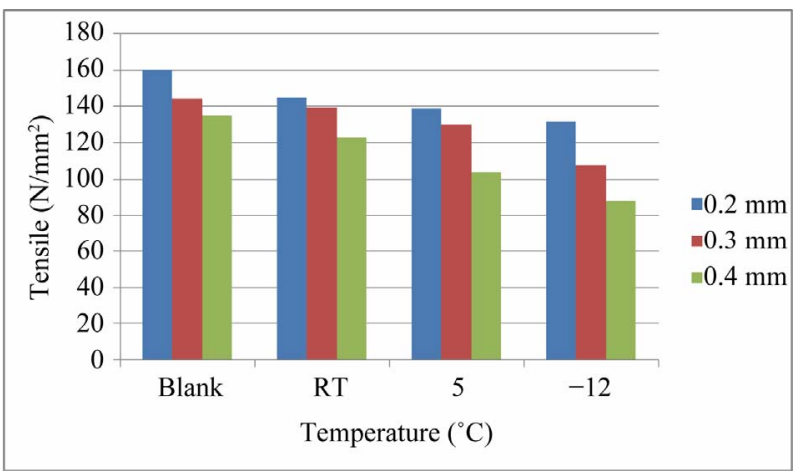

Figure 4. Tensile strength of insulation paper with $0.2,0.3$ and $0.4 \mathrm{~mm}$ thickness immersed in oil at $\mathrm{RT}, 5^{\circ} \mathrm{C}$ and $-12^{\circ} \mathrm{C}$ for 21 days.

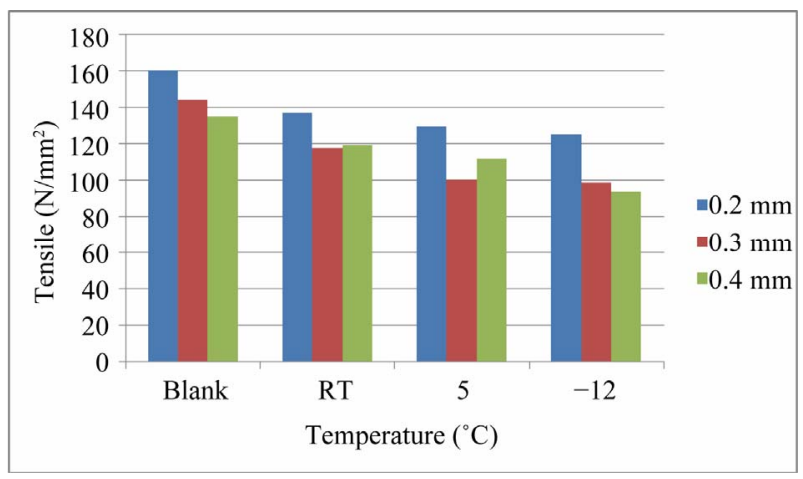

Figure 5. Tensile strength of insulation paper with $0.2,0.3$ and $0.4 \mathrm{~mm}$ thickness immersed in oil at $\mathrm{RT}, 5^{\circ} \mathrm{C}$ and $-12^{\circ} \mathrm{C}$ for 35 days.

Also from Figures 4-7, the effect of decreasing the temperature of the impregnation oil is cleared. It can be seen that, as the temperature decreased, the impregnated paper lost a part of its tensile strength. 


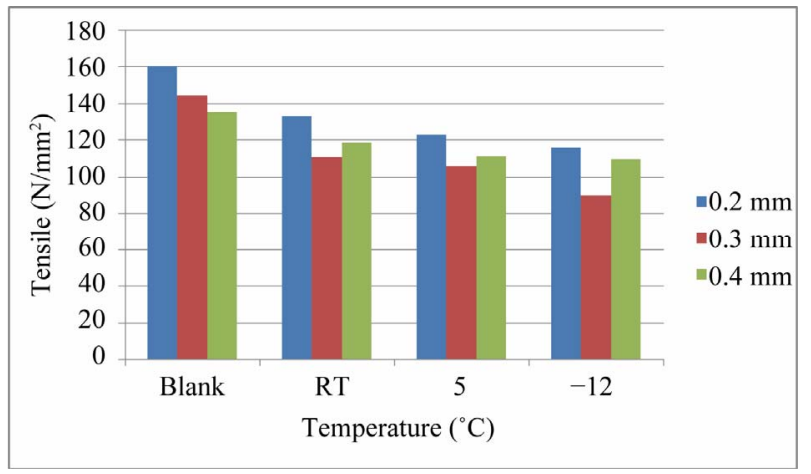

Figure 6. Tensile strength of insulation paper with $0.2,0.3$ and $0.4 \mathrm{~mm}$ thickness immersed in oil at $\mathrm{RT}, 5^{\circ} \mathrm{C}$ and $-12^{\circ} \mathrm{C}$ for 56 days.

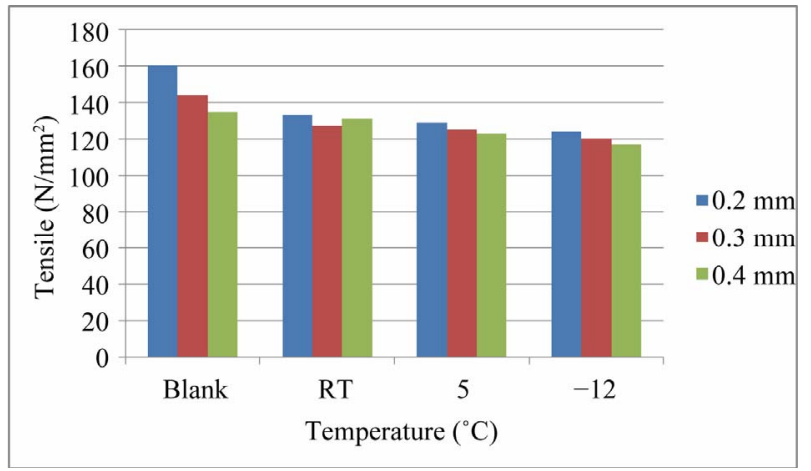

Figure 7. Tensile strength of insulation paper with $0.2,0.3$ and $0.4 \mathrm{~mm}$ thickness immersed in oil at $\mathrm{RT}, 5^{\circ} \mathrm{C}$ and $-12^{\circ} \mathrm{C}$ for 77 days.

The thickness of oil impregnated papers also plays an important role in resisting the impregnation effect. When the impregnation time was short ( 21 and 35 days), the deterioration of tensile strength was nearly the same for all samples. However, as the impregnation time increased, the higher thicknesses resisted more to degradation. This may be explained that the diffusion of the oil in higher thicknesses is weak and therefore, its effect on the cellulose chains is restricted.

\subsubsection{Effect on Water Content}

The $\%$ water content of oil impregnated papers is shown in Figures 8-11. The principal reactive sites of cellulose are the secondary hydroxyl groups located at positions C-2, C-3 and the primary $\mathrm{OH}$ at C-6 [12]. Water migrates to these sites and disrupts the hydrogen bonds between the cellulose molecules, destabilizing the paper matrix. It is well known that moisture moves between the insulation paper and dielectric fluid to reach equilibrium in terms of relative saturation $[13,14]$. In mineral oil/insulation paper system, the paper which has very low water content $(\sim 5 \%)$ will absorb water from oil at the beginning in order to keep equilibrium between oil and paper. However, when the oil and the air being relatively drier

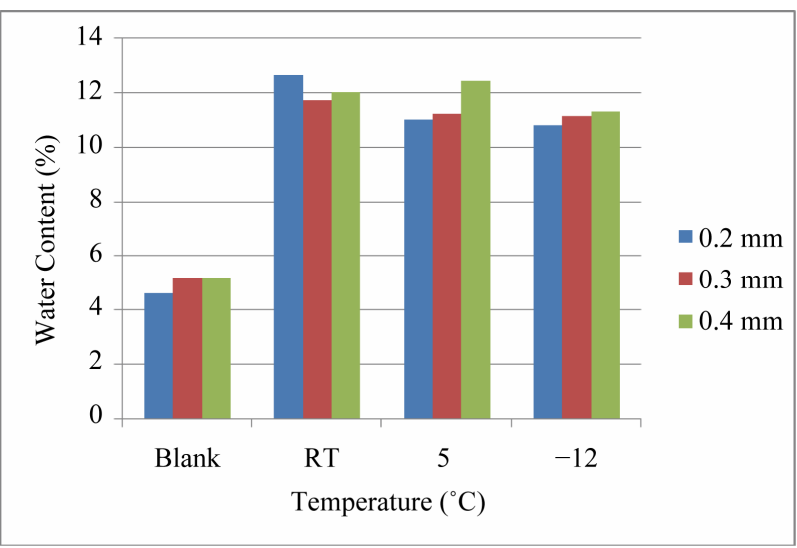

Figure 8. Water content of insulation paper with $0.2,0.3$ and $0.4 \mathrm{~mm}$ thickness immersed in oil at $\mathrm{RT}, 5^{\circ} \mathrm{C}$ and $-12^{\circ} \mathrm{C}$ for 21 days.

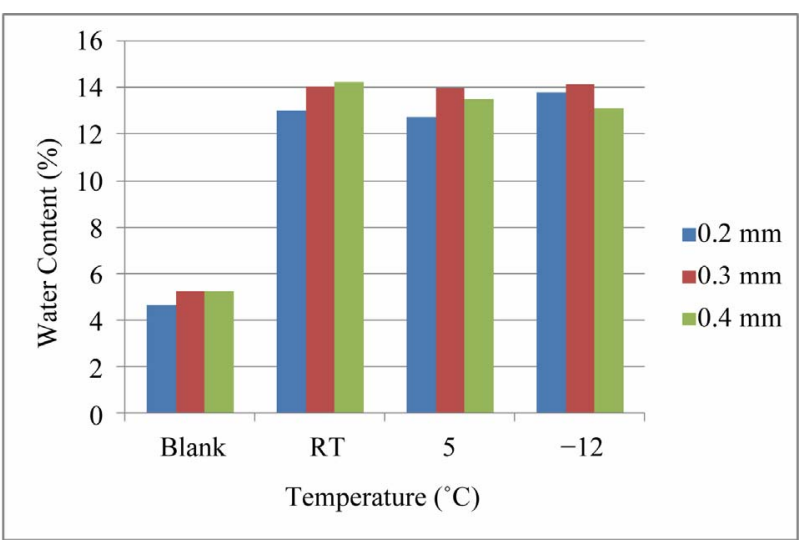

Figure 9. Water content of insulation paper with $0.2,0.3$ and $0.4 \mathrm{~mm}$ thickness immersed in oil at $\mathrm{RT}, 5^{\circ} \mathrm{C}$ and $-12^{\circ} \mathrm{C}$ for 35 days.

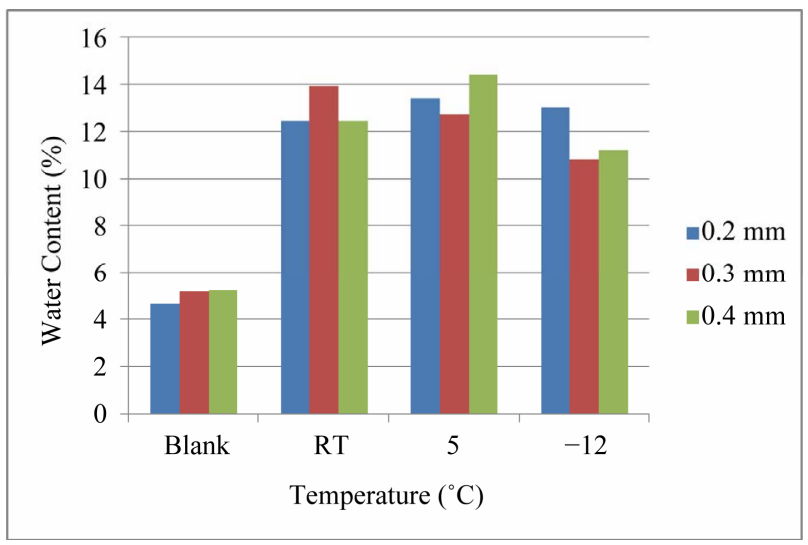

Figure 10. Water content of insulation paper with $0.2,0.3$ and $0.4 \mathrm{~mm}$ thickness immersed in oil at $\mathrm{RT}, 5^{\circ} \mathrm{C}$ and $-12^{\circ} \mathrm{C}$ for 56 days.

than the paper, there is always a migration of water from the paper to the oil and then to the air [15]. This may confirm the result that the water content of paper shows a decline as the water content of paper left for 77 days 


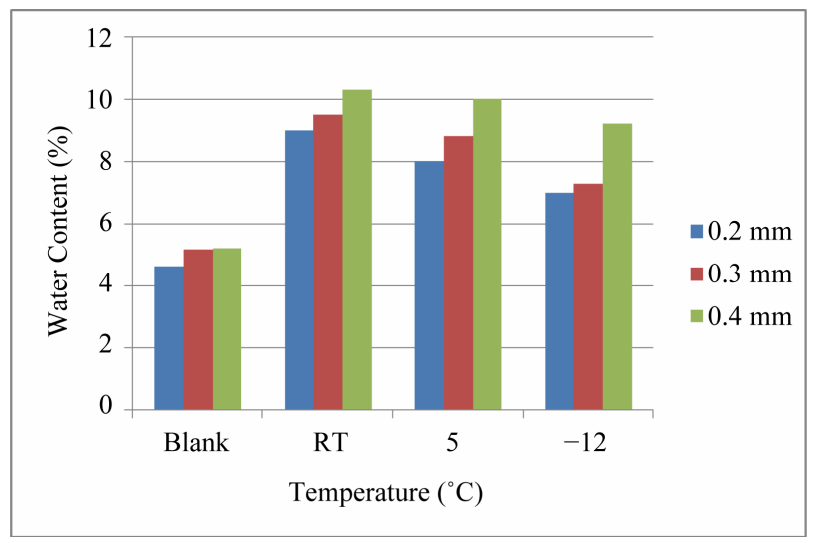

Figure 11. Water content of insulation paper with $0.2,0.3$ and $0.4 \mathrm{~mm}$ thickness immersed in oil at $\mathrm{RT}, 5^{\circ} \mathrm{C}$ and $-12^{\circ} \mathrm{C}$ for 77 days.

showed a decrease, and, accordingly, its tensile strength slightly increased. From Figures 8-11, it is clear that the water absorption decreased as the temperature decreased. This may be due to the higher viscosity of oil at low temperatures, which inhibited its diffusion in the paper. It is also clear that the difference in thicknesses between the insulation papers has almost a negligible effect on water absorption.

\subsection{Effect of Thermal Aging Properties of Oil Impregnated Insulation Paper}

To examine the ability of insulation paper for withstanding the environmental thermal conditions, all paper specimens were immersed in mineral oil at different temperatures $110^{\circ} \mathrm{C}, 130^{\circ} \mathrm{C}, 150^{\circ} \mathrm{C}$ and $170^{\circ} \mathrm{C}$ for 48,72 and 96 hours at each temperature.

\subsubsection{Effect on AC Breakdown Voltage}

Figure 12 shows the effect of increasing the temperatures from $110^{\circ} \mathrm{C}$ to $170^{\circ} \mathrm{C}$ on the breakdown voltage of oil impregnated insulation papers. The results plotted are those for specimen of insulation paper having $0.4 \mathrm{~mm}$ thickness for $96 \mathrm{hr}$. From this figure, it can be observed that, as the temperature increased, breakdown voltage decreased. Measurement at $170^{\circ} \mathrm{C}$ could not be carried out because the paper was separated to small pieces. Breakdown voltages are $13.75,12.50$ and $11.81 \mathrm{kV}$ for thermally aged paper at temperatures $110^{\circ} \mathrm{C}, 130^{\circ} \mathrm{C}$ and $150^{\circ} \mathrm{C}$, respectively.

Aging time plays an important role on breakdown voltage of oil impregnated papers. The relationship between thermal aging times (48, 72 and $96 \mathrm{hr})$ and breakdown voltages for oil impregnated papers with different thicknesses $(0.2,0.3$ and $0.4 \mathrm{~mm})$ at $110^{\circ} \mathrm{C}$ is presented in Figure 13.

It can be observed from this figure that, as the aging time increased, breakdown voltage decreased for each

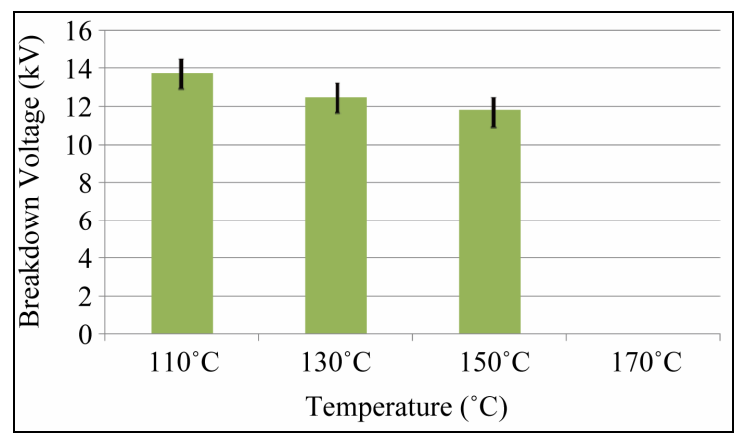

Figure 12. Breakdown voltage versus temperature for 0.4 mm thickness of oil impregnated paper for $96 \mathrm{hr}$.

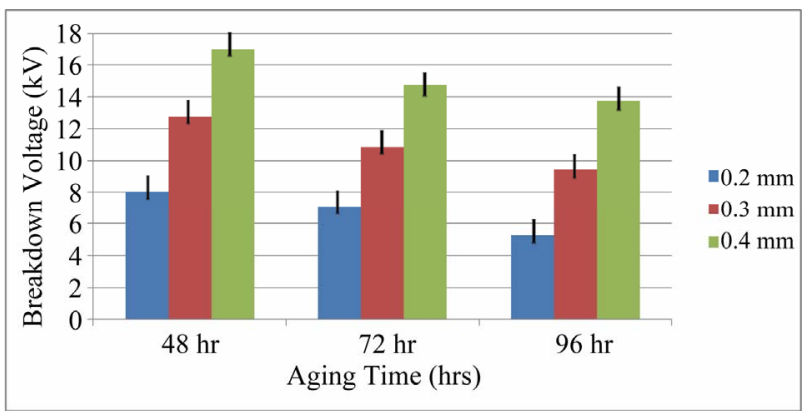

Figure 13. Thermal aging times against breakdown voltage of oil impregnated paper with different thicknesses at $110^{\circ} \mathrm{C}$.

paper thickness. Values of breakdown voltage were 8.03, 7.11 and $5.23 \mathrm{kV}$ for times 48,72 and $96 \mathrm{hr}$, respectively at $0.2 \mathrm{~mm}$ thickness of insulation papers. Values of breakdown voltage were $12.75,10.83$ and $9.43 \mathrm{kV}$ for times $48.72,96 \mathrm{hr}$, respectively, at $0.3 \mathrm{~mm}$ thickness of insulation papers. Also, values of breakdown voltage were $17.01,14.75$ and $13.75 \mathrm{kV}$ for same times at 0.4 $\mathrm{mm}$ thickness of insulation papers. The failure of breakdown voltage for the insulation paper at high aging temperature occurs due to the gradually damage of the cellulose surface, known as creep discharge [1].

Variation of paper thicknesses affected the breakdown voltage behavior at different thermal aging temperatures. Figure 14 shows values of breakdown voltages for various insulation paper thicknesses $(0.2,0.3$ and $0.4 \mathrm{~mm})$ at $110^{\circ} \mathrm{C}, 130^{\circ} \mathrm{C}$ and $150^{\circ} \mathrm{C}$ after 72 hours. It can be seen that increasing the thickness of insulation paper caused an increase in the breakdown voltage at each temperature. For example, increasing the thickness of paper from 0.2 $\mathrm{mm}$ to $0.3 \mathrm{~mm}$ and $0.4 \mathrm{~mm}$ at $110^{\circ} \mathrm{C}$ led to an increase in the breakdown voltages from 7.11 to 10.83 and $14.75 \mathrm{kV}$ respectively, while breakdown voltages were $5.69,10.01$ and $13.31 \mathrm{kV}$ for thicknesses $0.2,0.3$ and $0.4 \mathrm{~mm}$ respectively, at $130^{\circ} \mathrm{C}$. Also, breakdown voltages were $4.03,8.13$ and $12.73 \mathrm{kV}$ for insulation paper thickness $0.2,0.3$ and $0.4 \mathrm{~mm}$ respectively, at $150^{\circ} \mathrm{C}$. It can be noticed that, increasing the temperature from $110^{\circ} \mathrm{C}$ to 


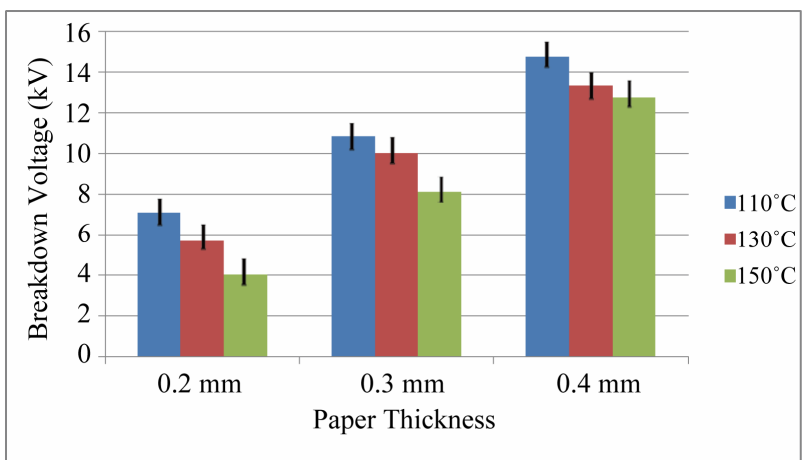

Figure 14. Oil impregnated paper thicknesses against breakdown voltage) at various temperatures for $72 \mathrm{hr}$.

$130^{\circ} \mathrm{C}$ and $150^{\circ} \mathrm{C}$ led to a decrease in the breakdown voltage of all insulation paper thicknesses.

It can therefore be concluded that thermal aging drastically affected the electrical performance of oil impregnated papers. Breakdown voltage of oil impregnated insulation paper decreased with aging time, which may be due to the degradation of paper [9].

\subsubsection{Effect on Tensile Strength}

Figures 15 and 16 show the effect of thermal aging on tensile strength of oil impregnated papers. It is clear that the increase in temperature caused a decrease in the tensile strength for all samples. High temperature led to cellulose degradation which consequently destroyed the interfibre bonding [16] and caused loss of mechanical properties. It is noticed also that the thickness of the paper has a negligible effect on the resistance of tensile strength to high temperatures. Moreover, it is clear that the deterioration in tensile strength slightly increased as the time of impregnation increased. Also, the temperature of the impregnation oil has a great effect on the tensile strength of paper. Impregnating the samples at $110^{\circ} \mathrm{C}$ for $48,72 \& 96 \mathrm{hr}$ resulted in a loss of $26.25 \%, 35 \%$ and $39 \%$ respectively of its original value. At $130^{\circ} \mathrm{C}$, the loss was $28.25 \%, 37.5 \%$ and $40 \%$ from its original value. It must be mentioned that higher temperatures were used $\left(150^{\circ} \mathrm{C}\right.$ and $\left.170^{\circ} \mathrm{C}\right)$ for different times, but in all cases, the resulting paper was too brittle to be tested, which means that the insulation paper reached end-of-life.

\subsubsection{Effect on Water Content}

Figures 17 and 18 show the effect of high temperatures $\left(110^{\circ} \mathrm{C}\right.$ and $\left.130^{\circ} \mathrm{C}\right)$ on the water content of oil impregnated insulation paper. It is clear that, for all samples, the water content increased by increasing the oil temperature. However, the water absorption at $110^{\circ} \mathrm{C}$ was higher than that at $130^{\circ} \mathrm{C}$. It can also be seen that the effect of the paper thickness on water content may be neglected. Figures 17 and 18 also show that the water content increased by increasing the time of impregnation from 48

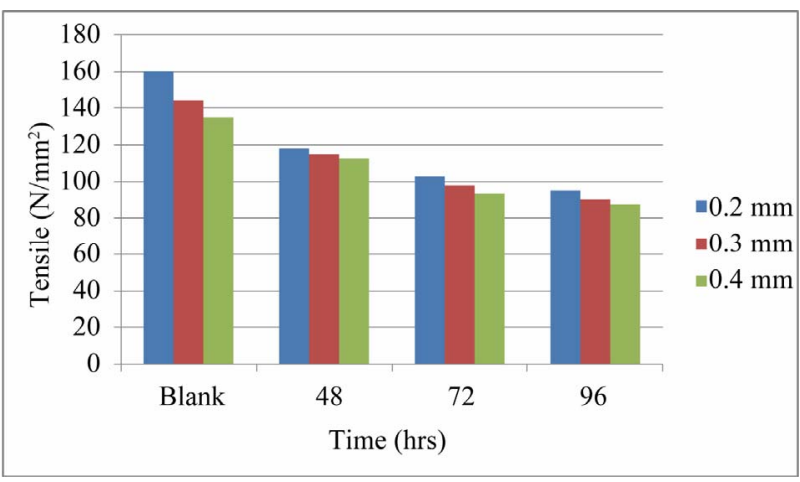

Figure 15. Tensile strength of insulation paper with $0.2,0.3$ and $0.4 \mathrm{~mm}$ thickness immersed in oil at $110^{\circ} \mathrm{C}$ for different times.

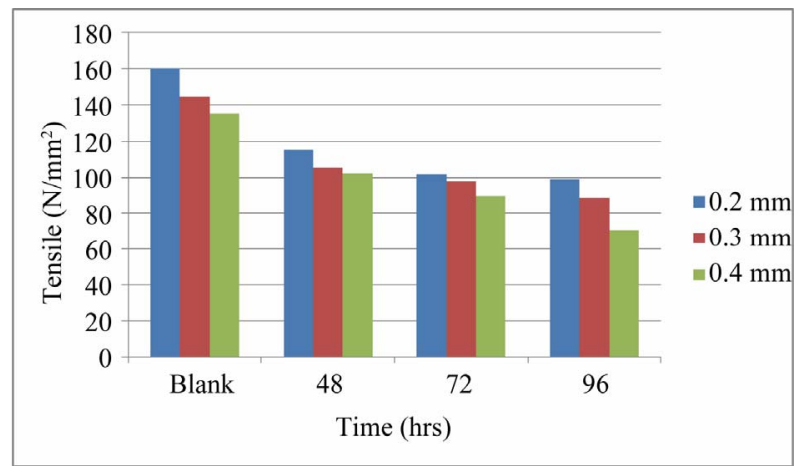

Figure 16. Tensile strength of insulation paper with $0.2,0.3$ and $0.4 \mathrm{~mm}$ thickness immersed in oil at $130^{\circ} \mathrm{C}$ for different times.

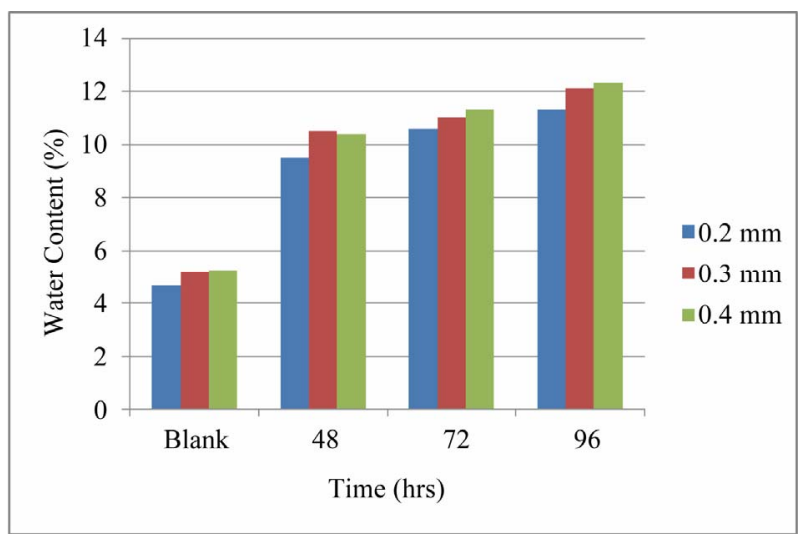

Figure 17. Water content of insulation paper with $0.2,0.3$ and $0.4 \mathrm{~mm}$ thickness immersed in oil at $110^{\circ} \mathrm{C}$ for different times.

to 72 and $96 \mathrm{hr}$.

\section{Conclusions}

This study has focused on the electrical and physical properties of oil impregnated insulation paper under different aging conditions. The results can be summarized as follows: 


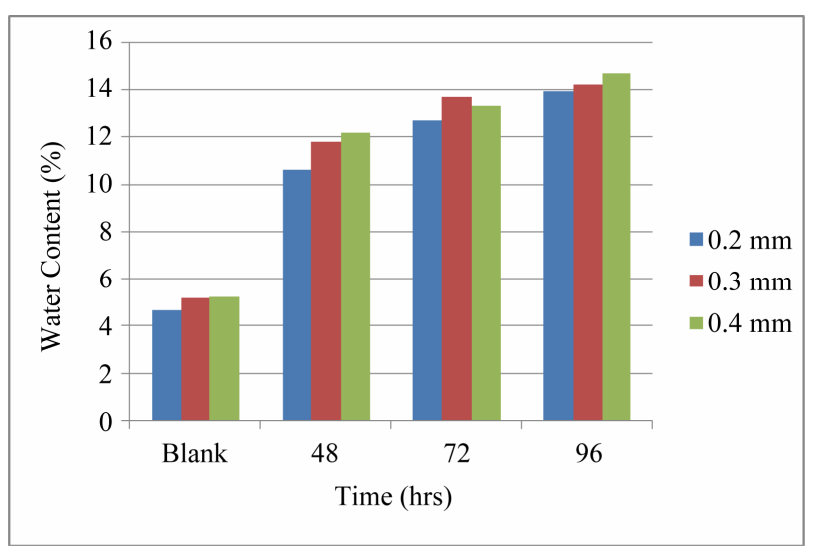

Figure 18. Water content of insulation paper with $0.2,0.3$ and $0.4 \mathrm{~mm}$ thickness immersed in oil at $130^{\circ} \mathrm{C}$ for different times.

1) AC breakdown voltage of insulation paper used for power transformers slightly increased at low temperature.

2) Thermal aging at $110^{\circ} \mathrm{C}, 130^{\circ} \mathrm{C}$ and $150^{\circ} \mathrm{C}$ drastically affected the electrical and mechanical performances of mineral oil impregnated papers. Breakdown voltage decreased by $14.11 \%$ for $0.4 \mathrm{~mm}$ thickness of paper insulation, when temperature increased from $110^{\circ} \mathrm{C}$ to $150^{\circ} \mathrm{C}$.

$3)$ Thickness of insulation paper $(0.2,0.3$ and $0.4 \mathrm{~mm})$ played an important role on the electrical characteristics of oil impregnated papers.

4) Tensile strength resisted to a certain extent to impregnation of paper for long times at low temperatures, but it is very much affected by high temperatures. At $130^{\circ} \mathrm{C}$, the loss in tensile strength was $28.25^{\circ} \mathrm{C}, 37.5^{\circ} \mathrm{C}$ and $40 \%$ from its original value for 48,72 and 96 hours, respectively.

5) Water content is an effective parameter in studying the mechanical properties of insulation paper. It is inversely proportional to the tensile strength.

\section{REFERENCES}

[1] R. J. Liao, J. Hao, G. Chen, Z. G. Ma and L. J. Yang, “A Comparative Study of Physicochemical, Dielectric and Thermal Properties of Pressboard Insulation Impregnated with Natural Ester and Mineral Oil," IEEE Transactions on Dielectrics and Electrical Insulation, Vol. 18, No. 5, 2011, pp. 1626-1637. doi:10.1109/TDEI.2011.6032833

[2] R. J. Liao, S. W. Liang, C. X. Sun, L. J. Yang and H. G. Sun, "A Comparative Study of Thermal Aging of Transformer Insulation Paper Impregnated in Natural Ester and in Mineral Oil," European Transaction on Electrical Power, Vol. 20, No. 4, 2010, pp. 518-523.

[3] J. Gerhold and T. Tanaka, "Cryogenic Electrical Insulation of Superconducting Power Transmission Lines: Transfer of Experience Learned from Metal Superconductors to High Critical Temperature Superconductors," Cryogenics, Vol. 38, No. 11, 1998, pp. 1173-1188.
doi:10.1016/S0011-2275(98)00105-2

[4] T. A. Prevost and T. V. Oommen, "Cellulose Insulation in Oil-Filled Power Transformers: Part I-History and Development," IEEE Electrical Insulation Magazine, Vol. 22, No. 1, 2006, pp. 28-35. doi:10.1109/MEI.2006.1618969

[5] H. G. Cheon, S. M. Baek, D. S. Kwag and S. H. Kim, "Comparison of Insulation Test of Mini-Models with Different Winding for a HTS Transformer," IEEE Tarnsactions on Applied Superconductivity, Vol. 16, No. 2, 2006, pp. 1497-1500. doi:10.1109/TASC.2005.865224

[6] J. M. Young, S. M. Baek and S. H. Kim, "Manufacturingand Test of Model Double Pancake Coils of HTS Transformers for Cryogenic Insulation Design," IEEE Transactions on Applied Superconductivity, Vol. 14, No. 2, 2004, pp. 928-931. doi:10.1109/TASC.2004.830321

[7] E. F. Pleva, V. Mehrotra and S. W. Schwentrly, "Conductor Requirements for High-Temperature Superconducting Utility Power Transformers," Superconductor Science and Technology, Vol. 23, No. 1, 2010, pp. 14-25.

[8] H. Z. Ding, Z. D. Wand and P. N. Janrman, "Effect of Ageing on the Impulse Breakdown Strength of Oil Impregnated Pressboard Used in Power Transformers," IEEE Conference on Electrical Insulation and Dielectric Phenomenon, Kansas City, 15-18 October 2006, pp. 497500.

[9] T. K. Saha and P. Purkait, "Understanding the Impacts of Moisture and Thermal Ageing on Transformer's Insulation by Dielectric Response and Molecular Weight Measurements," IEEE Transactions on dielectrics and Electric Insulation, Vol. 15, No. 2, 2008, pp. 568-582.

[10] K. Othmer, "Encyclopedia of Chemical Technology," 2nd Edition, Vol. 4, Wiley, New York, 1967.

[11] The Institute of Papermaking, "Appelton," Wisconsin Institute, Method No. 411, 1951.

[12] I. Rusznak and K. Zimmer, "Initial Processes in the Thermolysis of Cellulose Fibers," Proceedings of Hungarian Textile Conference, Vol. 2, 1971, pp. 119-139.

[13] K. J. Rapp, C. P. McShane and J. Lukisich, "Interaction Mechanisms of Natural Ester Dielectric Fluid and Kraft Paper," IEEE International Conference on Dielectric Liquids, Portugal, 26 June-1 July 2005, pp. 393-396. doi:10.1109/ICDL.2005.1490108

[14] K. Dumke, H. Borsi and E. Gockenback, "Fundamental Investigations on the Influence of Temperature and Water Content on the Electrical Behavior of Fluid Impregnated Insulating Papers," Conference Record of the 1996 IEEE International Symposium on Electrical Insulation, Montereal, 16-19 June 1996, pp. 542-545.

[15] T. V. Oommen, "Moisture Equilibrium Charts for Transformer Insulation Drying Practice," IEEE Transactions on Power Apparatus and Systems, Vol. 103, No. 10, 1984, pp. 3063-3067.

[16] R. Liao, C. Tang, L. Yang and S. Grzybowski, "Thermal Ageing Microscale Analysis of Power Transformer Pressboard," IEEE Transactions on Dielectrics and Electrical Insulation, Vol. 15, No. 5, 2008, pp. 1281-1287. 